\title{
PERAMALAN JUMLAH PRODUKSI HASIL PERTANIAN DI DENPASAR UTARA MENGGUNAKAN BAHASA SCRIPT AVENUE GIS
}

\author{
Ni Nyoman Supuwiningsih \\ Program Studi : Sistem Komputer \\ Jl. Puputan No.86 Renon Denpasar Bali \\ e-mail : supuwiningsih@stikom-bali.ac.id
}

\begin{abstract}
Agriculture is an activity in the utilization of natural resources conducted by humans to meet human needs, especially staple food Agricultural activities can produce foodstuffs, raw materials for industrial businesses, energy and can balance natural ecosystems. Formerly in Indonesia, agriculture is the main livelihood of the people because Indonesia is so fertile that whatever is planted can grow well. Over time all about the function of agriculture may have been forgotten by some people due to several factors such as population growth so that land conversion is done to housing, economic factors that do not allow to become farmers because most people think of it as Farmers of the future are not guaranteed so that people turn to other livelihoods which is considered promising and other factors such as opening shop, minister mini market and so on. Based on these problems, it is necessary to forecast the number of agricultural production using the Quadratic Trend Methods based on GIS application (Geographic Information System) using the script language Avenue. Avenue is a script or object-oriented programming language (OOP / Object Oriented Programming). This Avenue could be a new interface in ArcView, a repetitive work automation that does not yet exist in ArcView. Avenue is widely used to form the application information system based on ArcView GIS. Forecasting method used is quadratic trend method.
\end{abstract}

Keywords : Agriculture, Quadratic Trend Methods, GIS

\section{Abstrak}

Pertanian merupakan aktivitas dalam memanfaatkan sumber daya alam yang dilakukan oleh manusia untuk memenuhi kebutuhan manusia terutama bahan makanan pokok (Pertanian, K., 2013). Kegiatan pertanian dapat menghasilkan bahan makanan, bahan baku untuk perusahaan industri, energi dan dapat menyeimbangkan ekosistem alam. Pada jaman dahulu di Indonesia, pertanian merupakan mata pencaharian utama masyarakat karena Indonesia memiliki tanah yang subur sehingga apapun yang ditanam dapat tumbuh dengan baik. Seiring berjalannya waktu semua mengenai fungsi pertanian mungkin sudah dilupakan oleh sebagian orang karena beberapa faktor seperti pertambahan populasi penduduk sehingga dilakukan alih fungsi lahan menjadi perumahan, faktor ekonomi yang tidak memungkinkan menjadi petani karena kebanyakan masyarakat menganggap menjadi petani masa depan tidak terjamin sehingga masyarakat sudah beralih ke mata pencaharian lain yang dianggap sudah menjanjikan dan faktor lainnya seperti membuka toko, menjadi pelayan minimarket dan lain sebagainya. Berdasarkan permasalahan tersebut dibutuhkan peramalan jumlah produksi pertanian menggunakan metode tren kuadratis (Quadratic Trend Methods) berbasis GIS (Geographic Information System) aplikatif menggunakan bahasa script Avenue. Avenue adalah sebuah script atau bahasa pemrograman berorientasi object (OOP/Object Oriented Programming). Avenue ini dapat dibentuk sebuah interface baru pada ArcView, otomasi pekerjaan-pekerjaan yang bersifat berulang (repetitif) belum terdapat pada ArcView tersebut. Avenue banyak digunakan untuk membentuk sebuah sistem informasi aplikatif berbasis ArcView GIS. Metode peramalan yang digunakan adalah metode tren kuadratis.

Kata Kunci : Pertanian, metode tren kuadratis, GIS 


\section{PENDAHULUAN}

Pertanian merupakan aktivitas dalam memanfaatkan sumber daya alam yang dilakukan oleh manusia untuk memenuhi kebutuhan manusia terutama bahan makanan pokok (Pertanian, K., 2013). Kegiatan pertanian dapat menghasilkan bahan makanan, bahan baku untuk perusahaan industri, energi dan dapat menyeimbangkan ekosistem alam. Pada jaman dahulu di Indonesia, pertanian merupakan mata pencaharian utama masyarakat karena Indonesia memiliki tanah yang subur sehingga apapun yang ditanam dapat tumbuh dengan baik. Seiring berjalannya waktu semua mengenai fungsi pertanian mungkin sudah dilupakan oleh sebagian orang karena beberapa faktor seperti pertambahan populasi penduduk sehingga dilakukan alih fungsi lahan menjadi perumahan, faktor ekonomi yang tidak memungkinkan menjadi petani karena kebanyakan masyarakat menganggap menjadi petani masa depan tidak terjamin sehingga masyarakat sudah beralih ke mata pencaharian lain yang dianggap sudah menjanjikan dan faktor lainnya seperti membuka toko, menjadi pelayan minimarket dan lain sebagainya.

Berdasarkan fakta tersebut di daerah Denpasar Utara telah terjadi penurunan lahan pertanian dari tahun 2011-2014 sehingga dapat mempengaruhi jumlah produksi pertanian sebagai bahan makanan pokok (Supuwiningsih, N. N. 2015). Jumlah produksi tanaman pokok terutama padi mengalami penurunan yang signifikan pada tahun 2014. Berdasarkan hasil penelitian tersebut, penurunan luas lahan pertanian seharusnya menjadi perhatian yang sangat besar bagi pemerintah dan masyarakat untuk mencari solusi karena kurangnya informasi mengenai dampak alih fungsi lahan pertanian yang mempengaruhi hasil produksi sehingga kebutuhan pangan tidak terpenuhi.

Berdasarkan permasalahan tersebut dibutuhkan peramalan jumlah produksi pertanian menggunakan metode tren kuadratis (Quadratic Trend Methods) berbasis GIS (Geographic Information System) aplikatif menggunakan bahasa script Avenue. Avenue adalah sebuah script atau bahasa pemrograman berorientasi object (OOP/Object Oriented Programming). Avenue ini dapat dibentuk sebuah interface baru pada ArcView, otomasi pekerjaan-pekerjaan yang bersifat berulang (repetitif) belum terdapat pada ArcView tersebut. Avenue banyak digunakan untuk membentuk sebuah sistem informasi aplikatif berbasis ArcView GIS. Metode peramalan yang digunakan adalah metode tren kuadratis.

Metode tren kuadratis (Quadratic Trend Methods) merupakan metode tren yang sifatnya jangka pendek dan menengah, kemungkinan tren akan mengikuti pola linear (Suharyadi, Purwanto S.K. 2016). Hasil dari peramalan ini yang diimpelementasikan dengan peta digital dapat digunakan sebagai acuan kepada pemerintah dalam mengambil keputusan dan masyarakat dapat menyadari betapa pentingnya dalam mempertahankan pertanian.

\section{METODE PENELITIAN}

Metode yang digunakan dalam penelitian ini terdiri dari beberapa tahapan sebagai berikut :

1. Studi Literatur

Tahapan ini melakukan studi literatur berbagai referensi yang mendukung yang terdiri dari buku-buku dan jurnal-jurnal pendukung

2. Observasi lahan pertanian di wilayah Denpasar Utara

Melakukan pengamatan langsung ke wilayah Denpasar Utara, melihat lahan pertanian yang masih tersisa karena pengalihan lahan pertanian

3. Pengumpulan Data

Tahapan ini adalah mengumpulkan data-data luas lahan pertanian di wilayah Denpasar Utara dan jumlah produksi tanaman pertanian dari tahun 2011-2014, data ini digunakan sebagai acuan untuk meramalkan jumlah produksi tanaman pertanian dari tahun 20152019. Tanaman pertanian pokok yang ada di wilayah Denpasar utara adalah padi, kedelai, sayur hijau, sayur bayam, bawang merah, sayur kangkung dan kacang panjang.

4. Proses perhitungan peramalan

Tahapan ini melakukan perhitungan peramalan dengan menggunakan metode Metode tren kuadratis (Quadratic Trend Methods) 
5. Proses analisis data spasial dan data non spasial

Tahapan ini melakukan analisis data spasial yaitu wilayah Denpasar Utara secara Geografis dan data non spasial berupa atribut, jumlah produksi hasil pertanian tahun 2011-2014

6. Proses identifikasi Layer

Pada tahapan ini yaitu melakukan identifikasi masing-masing layer untuk digitasi

7. Proses kombinasi digitasi dengan bahasa script

Tahapan ini menggabungkan antara hasil digitasi dengan pemanggilannya menggunakan bahasa script Avenue. Sistematika penulisannya terdapat pada Gambar 1.

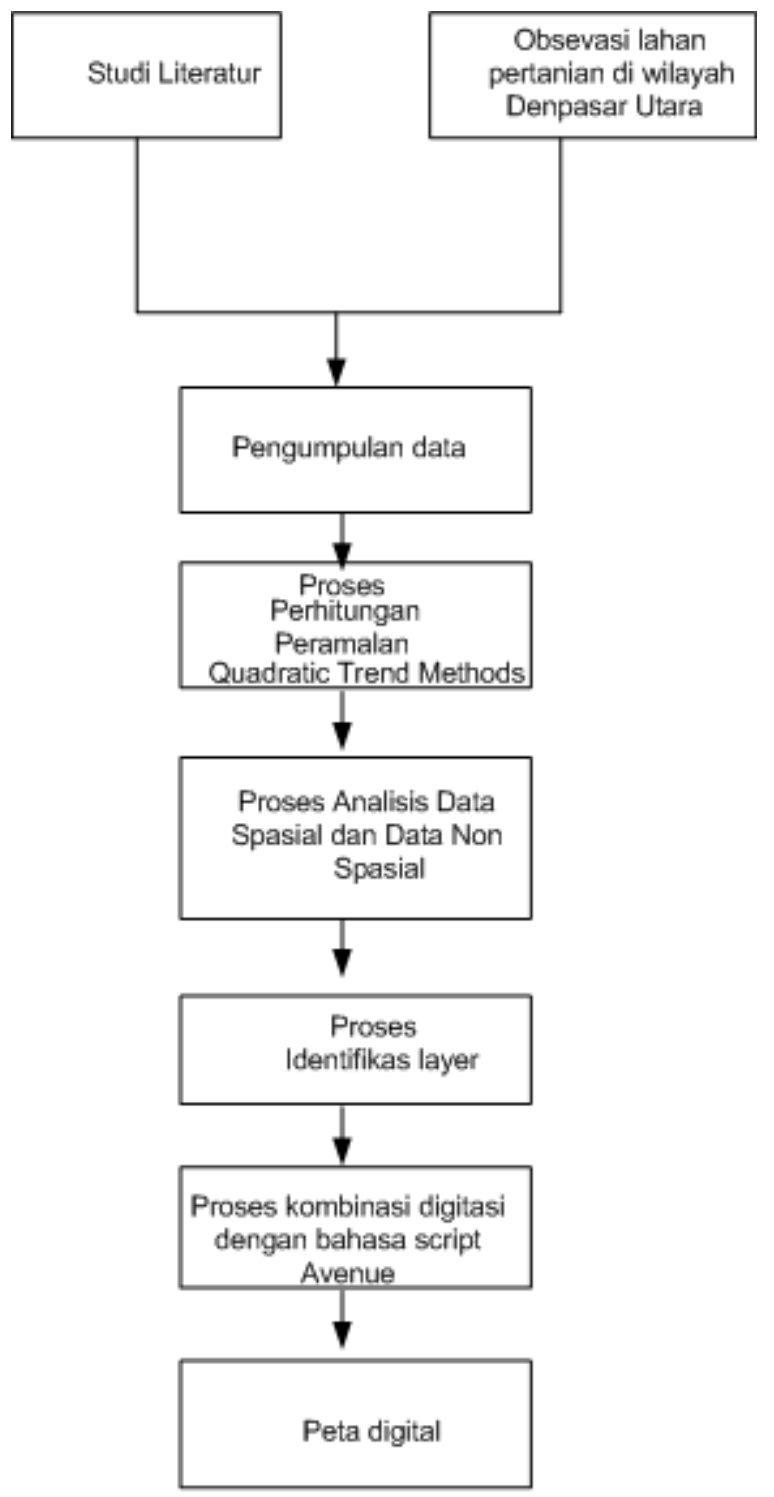

Gambar 1. Sistematika Penulisan

\section{HASIL PENELITIAN}

Perhitungan peramalan untuk jumlah produksi tanaman-tanaman pokok yang tumbuh di wilayah Kecamatan Denpasar Utara adalah sebagai berikut :

Perhitungan peramalan tanaman padi 
Tabel 1. Perhitungan Peramalan Jumlah Produksi Tanaman Padi di Denpasar Utara

\begin{tabular}{|l|l|l|l|l|l|l|}
\hline \multicolumn{1}{|c|}{ Tahun } & \multicolumn{1}{|c|}{$\mathrm{Y}$} & \multicolumn{1}{|c|}{$\mathrm{X}$} & \multicolumn{1}{|c|}{$\mathrm{XY}$} & \multicolumn{1}{|c|}{$\mathrm{X}^{2}$} & \multicolumn{1}{|c|}{$\mathrm{X}^{2} \mathrm{Y}$} & \multicolumn{1}{c|}{$\mathrm{X}^{4}$} \\
\hline 2011 & 6020 & -1.5 & -9030 & 2.25 & 13545 & 5.0625 \\
\hline 2012 & 7724 & -0.5 & -3862 & 0.25 & 1931 & 0.0625 \\
\hline 2013 & 7728 & 0.5 & 3864 & 0.25 & 1932 & 0.0625 \\
\hline 2014 & 5502 & 1.5 & 8253 & 2.25 & 12379.5 & 5.0625 \\
\hline Jumlah & 26974 & & -775 & 5 & 29787.5 & 10.25 \\
\hline
\end{tabular}

Persamaan kuadratis

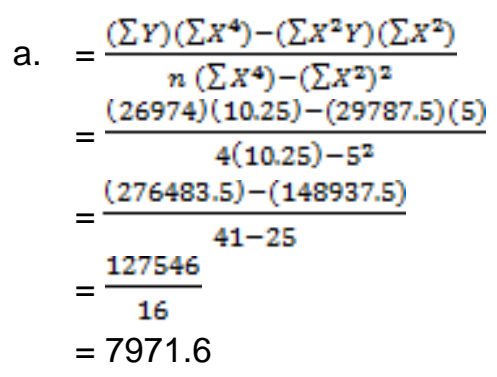

$$
\text { b. } \begin{aligned}
& =\frac{2 X Y}{\sum X^{2}} \\
& =\frac{-775}{5} \\
& =-155
\end{aligned}
$$

C. $=\frac{n\left(\sum x^{2} Y\right)-\left(\sum x^{2}\right)\left(\sum Y\right)}{n\left(\sum X^{4}\right)-\left(\sum X^{2}\right)^{2}}$

$=\frac{4(29787.5)-(5)(26974)}{4(10.25)-5^{2}}$

$=\frac{(119150-134870)}{(150)}$

$=\frac{-15720}{16}$

$=-982.5$

Jadi Persamaan kuadratisnya adalah $7971.6-155 X-982.5 X^{2}$

Peramalan jumlah produksi tanaman padi tahun $2015(X=2.5)$

$=7971.6-155 \mathrm{X}-982.5 \mathrm{X}^{2}$

$=7971.6-155(2.5)-982.5(2.5)^{2}$

$=7971.6-387.5-6140.6$

$=1443.5$

Peramalan jumlah produksi tanaman padi tahun $2016(X=3.5)$

$=7971.6-155 \mathrm{X}-982.5 \mathrm{X}^{2}$

$=7971.6-155(3.5)-982.5(3.5)^{2}$

$=7971.6-542.5-12035.6$

$=-4606.5$

Peramalan jumlah produksi tanaman padi tahun $2017(X=4.5)$

$=7971.6-155 \mathrm{X}-982.5 \mathrm{X}^{2}$

$=7971.6-155(4.5)-982.5(4.5)^{2}$

$=7971.6-697.5-19895.6$

$=-12621.5$

Peramalan jumlah produksi tanaman padi tahun 2018 ( $X=5.5)$

$=7971.6-155 \mathrm{X}-982.5 \mathrm{X}^{2}$

$=7971.6-155(5.5)-982.5(5.5)^{2}$

$=7971.6-852.5-29720.625$

$=-22601.5$ 
Peramalan jumlah produksi tanaman padi tahun 2019 ( $X=6.5$ )

$=7971.6-155 X-982.5 X^{2}$

$=7971.6-155(6.5)-982.5(6.5)^{2}$

$=7971.6-1007.5-41510.6$

$=-34546.5$

Tabel 2. Hasil Peramalan Tanaman Pokok di Denpasar Utara

\begin{tabular}{|l|l|l|l|l|l|l|l|}
\hline \multirow{2}{*}{ Tahun } & \multicolumn{7}{|c|}{ Hasil Peramalan Jumlah Produksi Tanaman Pokok (ton) } \\
\cline { 2 - 9 } & Padi & Kedelai & $\begin{array}{l}\text { Sayur } \\
\text { Hijau }\end{array}$ & $\begin{array}{l}\text { Sayur } \\
\text { Bayam }\end{array}$ & $\begin{array}{l}\text { Bawang } \\
\text { Merah }\end{array}$ & $\begin{array}{l}\text { Sayur } \\
\text { Kangkung }\end{array}$ & $\begin{array}{l}\text { Kacang } \\
\text { Panjang }\end{array}$ \\
\hline 2015 & 1443.5 & -102.3 & -3174.5 & -3566.4 & 37.7 & -4465.5 & 1.2 \\
\hline 2016 & -4606.5 & -432.5 & -9708.1 & -6730.6 & 25.5 & -13015.5 & -24.8 \\
\hline 2017 & -12621.5 & -864.2 & -18151.7 & -10759.3 & 10.85 & -24342.5 & -58.3 \\
\hline 2018 & -22601.5 & -1397.4 & -4419.8 & -15652.5 & -6.35 & -38446.5 & -99.3 \\
\hline 2019 & -34546.5 & -2032.1 & -40768.9 & -21410.2 & -26.05 & -55327.5 & -147.8 \\
\hline
\end{tabular}

Pada Tabel 2 merupakan hasil peramalan dari tahun 2015-2019 untuk semua tanaman pokok yaitu padi, kedelai, sayur hijau, sayur bayam, bawang merah, sayur kangkung dan kacang panjang. Implementasi ke ArcView wilayah Denpasar Utara dapat dilihat pada Gambar 2.

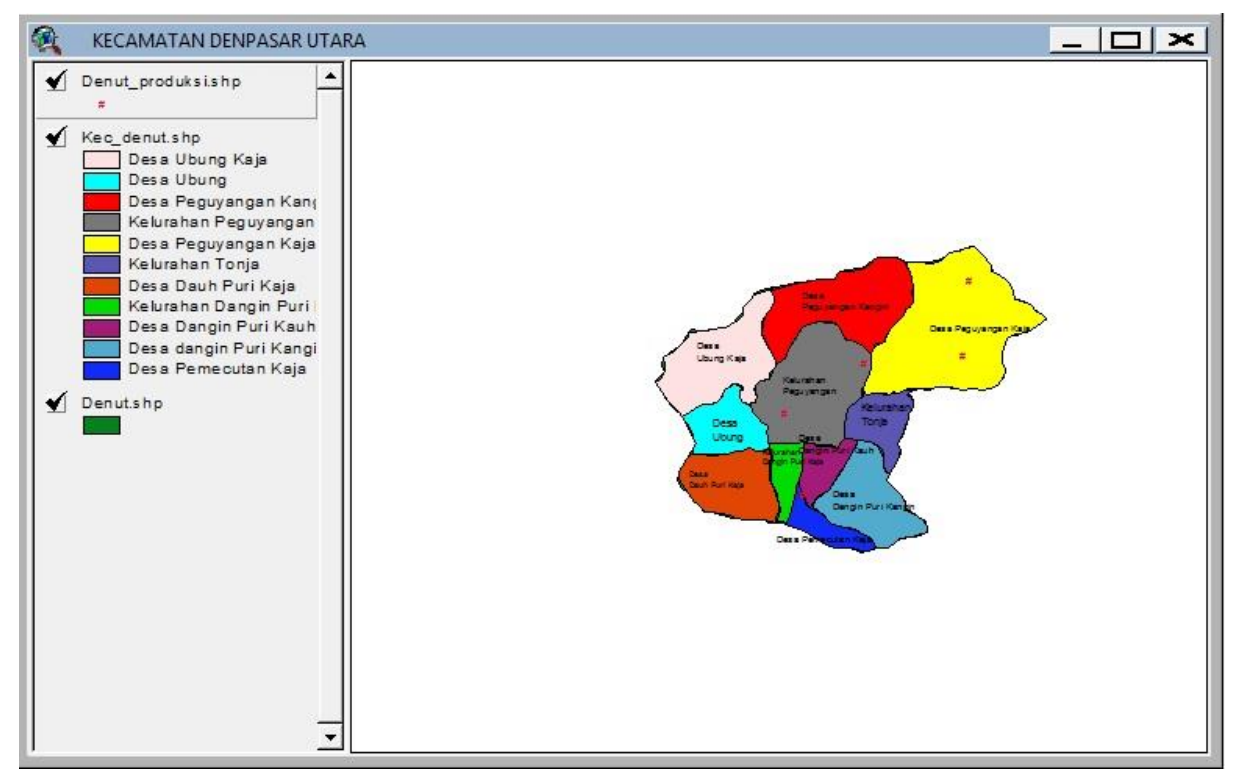

Gambar 2. Hasil Digitasi Peta Denpasar Utara

Data non spasial /data atribut dalam ArcView dapat dilihat pada Gambar 3 berikut ini yaitu terdiri dari data jumlah produksi pertanian tahun 2011-2014 dan data non spasial hasil peramalan jumlah produksi pertanian dari tahun 2015-2019.

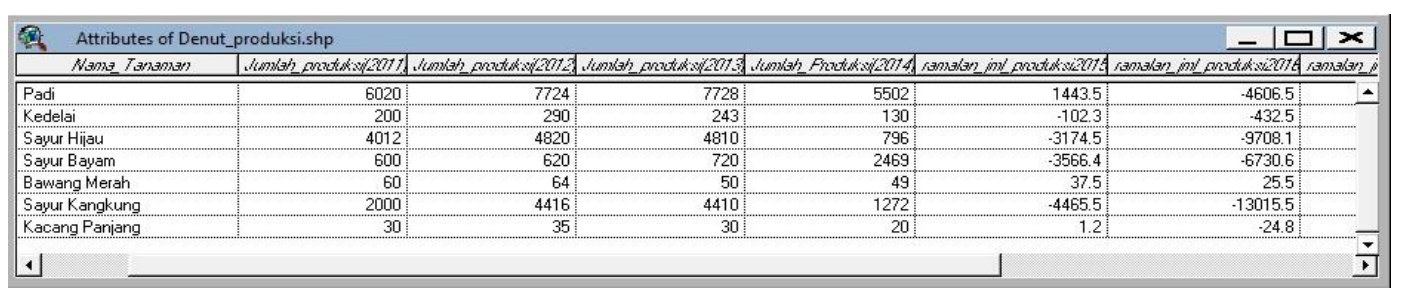

Gambar 3. Data Non Spasial Jumlah Produksi dan Hasil Peramalan Hasil Produksi Pertanian 
Pada Gambar 4 adalah bahasa script Avenue yang menggabungkan dengan digitasi peta di ArcView berbasis desktop.

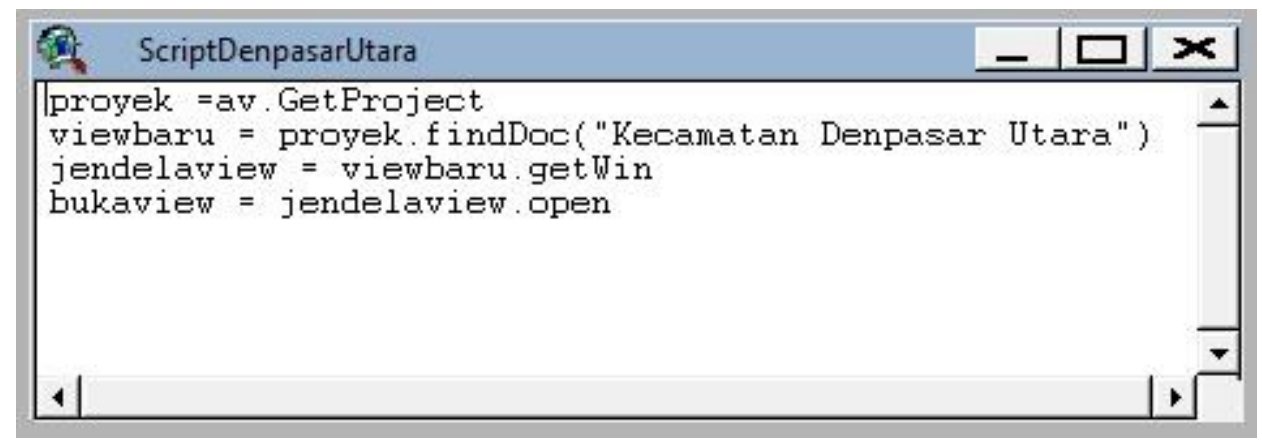

Gambar 4. Bahasa Script Avenue

Grafik peramalan jumlah produksi pertanian dari tahun 2015-2019 terlihat pada Gambar 5.

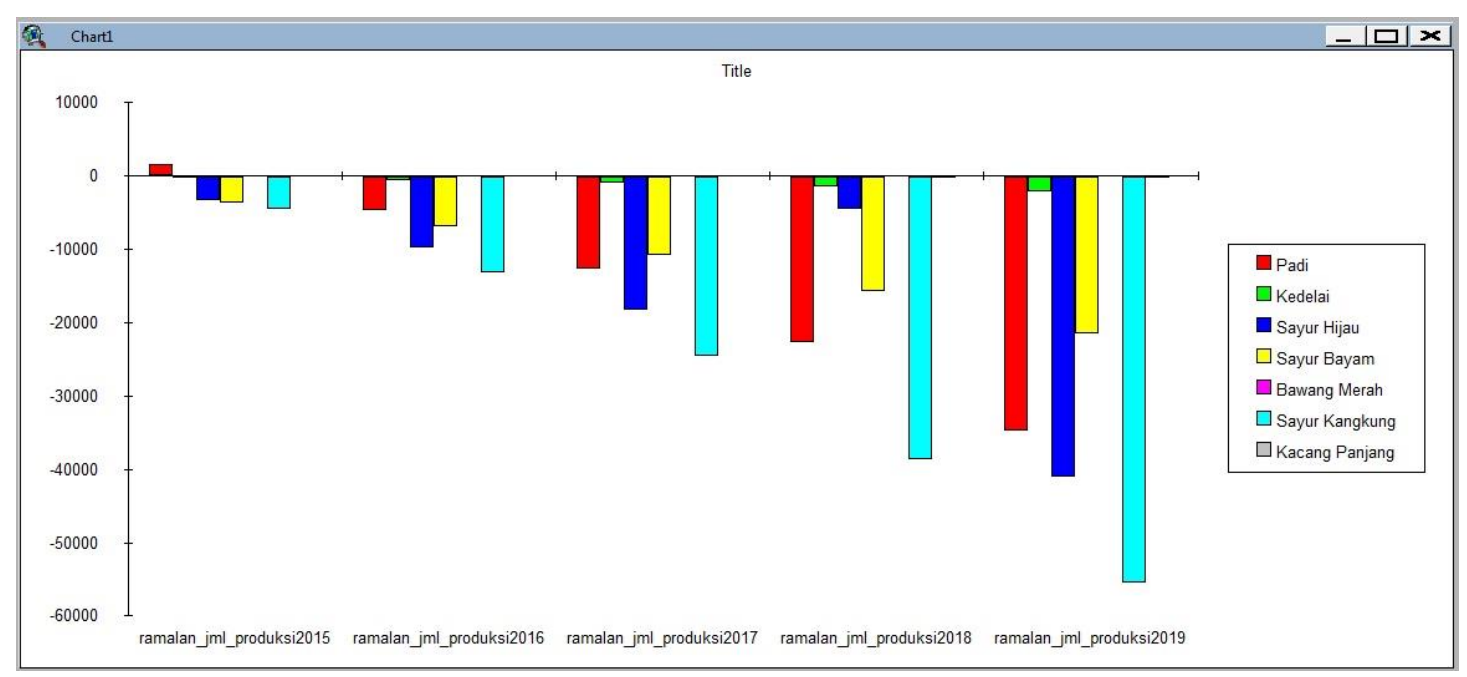

Gambar 5. Grafik Peramalan Jumlah Produksi

\section{PEMBAHASAN}

Berdasarkan hasil penelitian peramalan jumlah produksi hasil pertanian di wilayah Denpasar Utara. Hasil pertanian yang merupakan tanaman pokok di Denpasar Utara berupa tanaman padi, kedelai, sayur hijau, sayur bayam, bawang merah, sayur kangkung dan kacang panjang. Jumlah produksi hasil pertanian yang diamati dari tahun 2011-2014 selalu mengalami penurunan terutama tanaman padi seiring dengan menyempitnya luas lahan pertanian. Berdasarkan hasil perhitungan peramalan menggunakan metode tren kuadratis (Quadratic Trend Methods) terjadi penurunan jumlah produksi dengan nilai minus, ini artinya penurunannya terjadi secara signifikan. Hal ini sebaiknya menjadi perhatian yang sangat serius bagi pemerintah dan masyrakat dalam mengatasi hal ini supaya tidak terjadi di masa yang akan datang. Hasil peramalan tersebut diimplementasikan ke dalam sistem informasi geografis dalam bentuk peta digital yang mengkombinasikan dengan bahasa script Avenue dalam ArcView berbasis desktop. Sistem informasi geografis ini mampu memberikan informasi mengenai data non spasial hasil peramalan jumlah produksi pertanian di wilayah Denpasar Utara. 


\section{KESIMPULAN}

Berdasarkan hasil penelitian maka dapat disimpulkan bahwa:

1. sesuai dengan hasil perhitungan dengan menggunakan metode tren kuadratis (Quadratic Trend Methods) terjadi penurunan jumlah produksi pertanian yang sangat drastis sampai mencapai angka minus.

2. Hasil penelitian ini dapat digunakan sebagai referensi untuk pemerintah terutama di bagian pertanian untuk mencari solusi alternatif dalam rangka menyelamatkan jumlah produksi pertanian serta lahan pertanian yang semakin menyempit karena salah satu faktor populasi penduduk terutama di wilayah Denpasar Utara

3. Adanya sistem informasi geografis ini diharapkan dapat membantu masyarakat bekerja sama dengan pemerintah dalam mengembangkan pertanian dengan teknologi modern.

\section{DAFTAR PUSTAKA}

Adnyana, I.W.S., As-Syakur, A.R., 2012, Aplikasi SIG Berbasis Data Raster untuk Pengkelasan Kemampuan Lahan di Provinsi Bali dengan Metode Nilai Piksel Pembeda, Jurnal Manusia dan Lingkungan, No. 1, Vol. 19, 21-29.

Barus, B., Panuju, Munibah, K., Iman, L.S., Tri Sasongko, B.H., Widiana.N., Kusumo, R., 2012, Model Pemetaan Sawah dan Perlindungan Lahan Pertanian Pangan dengan Penginderaan Jauh dan SIG, Seminar dan Ekspose Hasil Kegiatan dan Penelitian P4W LPPM, Bogor, 11 Desember 2012

Budiyanto Eko. (2007). Avenue : untuk Pengembangan Sistem Informasi Geografis. Yogyakarta : Andi Yogyakarta

Denpasar, P. k., 2016, Profil Kota Denpasar, www.denpasarkota.go.id, diakses tanggal 23 Juni 2016

Gunawan, B., 2011, Pemanfaatan Sistem Informasi Geografis untuk Analisa Potensi Sumber Daya Lahan Pertanian di Kabupaten Kudus, Jurnal Sains dan Teknologi, No. 4, Vol. 4, $122-132$.

Heddy, S., 2010, Agrosistem : Permasalahan Lingkungan Pertanian, Raja Grafindo, Jakarta.

Hendro, H., Nadhi, Z., Budiastuti, S., Purnomo, D., 2014, Pemetaan Lahan Kritis di Kawasan Muria untuk Meningkatkan Daya Dukung Lingkungan yang Berbasis pada Sistem Informasi Geografis (SIG), Jurnal Ilmu Pertanian, No. 1, Vol. 17

Nahdi, Z., Hendro, H., Supriyo, H., Solekhan, (2014), Implementasi Sistem Informasi Geografi untuk Inventarisasi Data Komoditas Pertanian dan Informasi Kondisi Lahan di Kabupaten Kudus, Jurnal IImu Pertanian, No. 1, Vol. 17, 52-89.

Pertanian, K., 2013, Statistik Lahan Pertanian, Pusat Data dan Sistem Informasi Pertanian Sekretariat Jenderal Kementerian Pertanian, Jakarta.

Prahasta Eddy. (2002). Sistem Informasi Geografis : Tutorial ArcView. Bandung : Informatika Bandung

Prahasta Eddy. (2004). Sistem Informasi Geografis : ArcView Lanjut. Bandung : Informatika Bandung

Prahasta Eddy. (2004). Sistem Informasi Geografis : Tools dan Plug-Ins. Bandung : Informatika Bandung

Rahmawati, N., Saputra, R., Sugiharto, A., 2013, Sistem Informasi Geografis Pemetaan dan Analisis Lahan Pertanian di Kabupaten Pekalongan, Journal of Informatics and Technology, No. 1, Vol.2, 95-101, http://ejournal-s1.undip.ac.id/index.php/joint

Statistik, B. P. (2017, Mei 23). Badan Pusat Statistik Provinsi Bali. Retrieved from BPS Web site: http://www.bps.go.id/

Suharyadi. Purwanto S.K. (2016). Statistik untuk Ekonomi dan Keuangan Modern. Jakarta: Salemba Empat.

Supuwiningsih, N. N. (2015). Implementasi Geograhic Information System untuk Pemetaan Lahan Pertanian Kota Denpasar. Denpasar: STIKOM Bali.

Supuwiningsih, N. N. (2016). Analisis Hasil Pertanian di Kota Denpasar dengan Menggunakan Sistem Informasi Geografis. Denpasar : STIKOM Bali.

Supuwiningsih, N.N., Rusli, M. (2017), Prediction of Decreasing Agricultural Land Based on Geographic Information System Case Study : Denpasar City, Internation Journal of Computer Applications, vol.162, No.9 , 0975-8887. 